\title{
Article
}

\section{The role of psychological characteristics in facilitating the pathway to elite performance. Part 1: Identifying mental skills and behaviours}

MacNamara, Á., Button, A., and Collins, D.

Available at http://clok.uclan.ac.uk/4826/

MacNamara, Á. ORCID: 0000-0002-8110-6784, Button, A., and Collins, D. ORCID: 0000-0002-7601-0454 (2010) The role of psychological characteristics in facilitating the pathway to elite performance. Part 1: Identifying mental skills and behaviours. The Sport Psychologist, 24 (1). pp. 52-73. ISSN 08884781

It is advisable to refer to the publisher's version if you intend to cite from the work.

For more information about UCLan's research in this area go to http://www.uclan.ac.uk/researchgroups/ and search for <name of research Group>.

For information about Research generally at UCLan please go to http://www.uclan.ac.uk/research/

All outputs in CLoK are protected by Intellectual Property Rights law, including Copyright law. Copyright, IPR and Moral Rights for the works on this site are retained by the individual authors and/or other copyright owners. Terms and conditions for use of this material are defined in the policies page. 


\title{
The Role of Psychological Characteristics in Facilitating the Pathway to Elite Performance Part 1: Identifying Mental Skills and Behaviors
}

\author{
Áine MacNamara \\ University of Limerick \\ Angela Button \\ University of Otago \\ Dave Collins
}

University of Lancashire and P2E Consulting

\begin{abstract}
Given the complexity of the talent development process, it seems likely that a range of psychological factors underpin an athlete's ability to translate potential into top-class performance. Therefore, the purpose of part one of this two-part investigation was to explore the attributes that facilitate the successful development of athletes from initial involvement to achieving and maintaining world-class status. Seven elite athletes and a parent of each of these athletes were interviewed regarding their own (their son's/ daughter's) development in sport. Data were content analyzed using a grounded theory approach. Although sporting achievement was conceptualized as being multidimensional, psychological factors were highlighted as the key determinants of those who emerged as talented and maintained excellence. Accordingly, we suggest that talent identification and development programs should place greater emphasis on the advancement and application of psychological behaviors at an early stage to optimize both the development and performance of athletes.
\end{abstract}

Considerable research evidence attests to the role of psychological factors as determinants of elite performance. Orlick and Partington (1998), for example, identified psychological "success factors" (e.g., high level of commitment, long and short term goals, imagery, focus, pre- and in-competition plans) that distinguished successful athletes from their less successful counterparts. Supporting these find-

MacNamara is with the Dept. of Physical Education and Sport Science, University of Limerick, Ireland. Button is with the University of Otago, Dunedin, New Zealand. Collins is Professor of Coaching and Performance, University of Lancashire and is with P2E Consulting, United Kingdom. 
ings, Gould and colleagues found that successful Olympic athletes were more committed and focused, and engaged in more extensive mental preparation than less successful performers (Gould, Diffenbach, \& Moffett, 2002). Further support for this contention comes from Durand-Bush and Salmela's work (2002) with Olympic and World champions. They identified, among others, self-confidence and motivation as salient psychological characteristics of these elite athletes. In addition, these champions employed imagery and self-talk to both prepare for competition and to remain focused during high-level performances.

Despite this almost universal acceptance of psychological factors as characteristic of those who compete at the highest level (Gould et al., 2002; Orlick \& Partington, 1998; Williams \& Krane, 2001), their possible role in reaching this level is comparatively neglected. Kunst and Florescu highlighted the crucial role of psychological factors in talent development as early as 1971, suggesting that these constructs accounted for over $50 \%$ of the variance in development efficacy-the ability to progress effectively. They also noted that, in contrast, psychological factors accounted for less than $15 \%$ of talent development models at that time. Regrettably, that situation does not appear drastically different in the current climate with Talent Identification and Development (TID) models continuing to place limited emphasis on the role of psychological factors and instead employing testing protocols based almost entirely on current performance (e.g., how well an athlete performs at that particular moment in time) or physical/anthropometric characteristics (e.g., how similar they are to 'established norms' for elites; Abbott \& Collins, 2002; Regnier, Salmela, \& Russell, 1993). These TID models seem to ignore the identification and systematic development of those factors that enable individuals to successfully cope with the 'ebb and flow' of the road to excellence (Durand-Bush \& Salmela, 2002): in short, those factors that may form the mechanisms for achieving success. When this omission is coupled with the low predictive value of such TID models (Abbott \& Collins, 2002), it emphasizes the need to consider the multiple components that facilitate the effective evolution of potential into achievement.

Given the need to invest considerable time and effort into one's activity to achieve excellence (cf., Thomas \& Thomas, 1999) it is not surprising that attitudes and behaviors facilitative of deliberate practice are associated with effective development (Bailey \& Morley, 2006). For example, MacNamara, Holmes, and Collins (2006; 2008), and Kamin and colleagues (Kamin, Richards, \& Collins, 2007), found that a range of psychological characteristics (e.g., commitment, motivation, determination) facilitated the development of elite classical and nonclassical musicians. In a similar manner, Baker and Horton's (2004) review of primary and secondary influences on sport expertise suggests that psychological characteristics play a central role, and are necessary for both the acquisition and manifestation of expertise. Determination and persistence (Bloom, 1985; Renzulli, 1986), motivation (Singer \& Orbach, 1999; Ward, Hodges, Williams, \& Starkes, 2004), and autonomy (Schoon, 2000) have all been highlighted as factors necessary for the attainment of excellence by facilitating the acquisition of skills and enabling athletes to invest the requisite time to practice and stay committed to the development process.

Emphasizing the factors that underpin development is particularly salient given that the pathway to excellence is rarely smooth (Abbott, Button, Pepping, 
\& Collins, 2005), although effective completion of the journey is the key to the realization of potential. The aspiring elite must pass through various stages of development as they progress (e.g., sampling, specialization, investment; Bloom, 1985; Côté, 1999), recognizing that the requirements to achieve (e.g., amounts of deliberate practice; Ericsson \& Charness, 1994) change with this progression. This stage-approach clearly highlights the evolutionary, dynamic, and complex interactions that must be addressed to optimize development rather than viewing talent as the 'all or nothing' phenomenon it is sometimes regarded to be (van TasselBaska, 2001). Simonton (2001) expanded this perspective by proposing that the development of talent is dynamic and emerges over time, both endogenously and in reaction to environmental factors. Simonton's model of development accounts for the multiple factors that influence talent and suggests that these factors (e.g., innate ability, psychomotor factors, environmental factors, motivation, learning strategies) interact in a multiplicative manner. This consideration is important given that excellence in sport is not idiosyncratic to a specific set of attributes but can be achieved through a combination of skills and capabilities (Feldman, 1988). What should be of real interest to those involved in TID is the composition of skills, behaviors, and capabilities that allow individuals to make the most of the opportunities presented during development and translate their potential into capability (Abbott \& Collins, 2004; Bailey \& Morley, 2006; Howe \& Davidson, 2003; Lidor \& Lavyan, 2002).

Accordingly, the purpose of this two-part investigation was to examine the careers of successful athletes to identify the attributes perceived to have contributed to their development into successful and consistent world-class performers. The first examination was facilitated through retrospective interviews with world-class athletes and their parents, to gain an insight into the factors perceived to have enabled their own success against the challenges they had to overcome. In a follow up study (MacNamara, Button, \& Collins, 2010), we then examined the specificity of these factors and their deployment, with regard to performance domain and timing relative to the pathway to excellence.

In pursuing these critical issues, it was necessary to make careful methodological decisions. Although longitudinal studies would provide the best insights into the developmental process there are difficulties, in terms of time and cost constraints against quality of return, in conducting such research. Most crucially, given the relative inefficiency of even the best TID schemes (Abbott \& Collins, 2002), one would have to start with a very large participant pool, and allow for a substantial degree of 'mortality' to finish with a meaningful sample. Nevertheless, retrospective studies with elites, despite their obvious limitations (i.e., self-report bias, truthfulness, reliability; Patton, 2002), have provided significant insight into the attributes perceived to impact on talent development (e.g., Lidor \& Lavyan, 2002; Thomas \& Thomas, 1999). The involvement of a parent for each of the participants enriched the data while also countering some of the 'rosy glow' and self presentational interpretations which may contaminate retrospective accounts. This step was deemed particularly important for participants who were involved in a highly competitive pathway. Thus, while the limitations of retrospective research are acknowledged, we selected this approach as the best option at this initial stage of investigation. 


\section{Method}

\section{Participants}

Data were collected from separate interviews with female $(n=4)$ and male $(n=$ 3 ) world-class athletes and a parent for each participant $(n=7)$. The ages of the athletes ranged from 21 to 37 years $(M=30.1$ years, $S D=5.0$ years $)$ and all had competed at the top of their sport for between 4 and 13 years $(\mathrm{M}=7.5$ years, $S D$ $=2.8$ years). At the time of the interview, five of the athletes continued to participate in senior international competitions while two of the athletes had retired from international competition within the preceding two years. Additional demographic and sporting information for all athletes is presented in Table 1.

\section{Procedure}

Ethical approval was granted from the author's institutional ethics committee and informed consent was obtained from all participants. Before meeting the athletes and parents, a semistructured interview designed to explore attributes perceived to have facilitated the development of the athletes within their sport was developed (see Table 2). Follow-up probes were prepared for each area of interest to allow the focus to move from the general to the specific. Confidentiality was assured. Interviews lasted between 90 and 120 min, supplemented by an introduction and briefing.

\section{Data Analysis}

Interviews were transcribed in full and content analyzed. Inductive content analysis, which allows themes and categories to emerge from the data, was employed following the recommendations of Côté and colleagues (Côté, Salmela, Baria, \& Russell, 1989). Athletes' quotations were used to depict the raw data themes that formed the first level of analysis of the data. Following the recommendations of Krane, Andersen, and Strean (1997), a reliability check was conducted at this stage by asking an independent investigator, blind to the objectives of the study, to critically question the summary statements to ensure that they accurately reflected quotations. Once these data were compiled, an inductive analysis of the data were undertaken to generate higher order themes that linked similar raw data themes together into a higher-order concept. The inductive process of comparing and contrasting continued until it was deemed not possible to locate further underlying uniformities to create a higher-level theme. This process allowed for the continuous refinement of the results throughout the analysis process until theoretical saturation was met (Strauss \& Corbin, 1998).

Validity was checked using respondent validation techniques (Patton, 2002) where the participant checked the report to ensure the accuracy of the content, and satisfaction with the veracity of the overarching terms and constructs. Several further steps were taken to ensure the validity and trustworthiness of the data presented. In qualitative research, the researcher becomes an instrument through which the data must pass for analysis. Accordingly, and recognizing the risk for miscoding and misclassification of meaning units, a collaborative approach was taken with an independent researcher, blind to the conditions and objectives of the investigation, coding part of the data (Rose \& Jevine, 1993). When this process resulted in an analytic disagreement both researchers presented their interpretations until a 


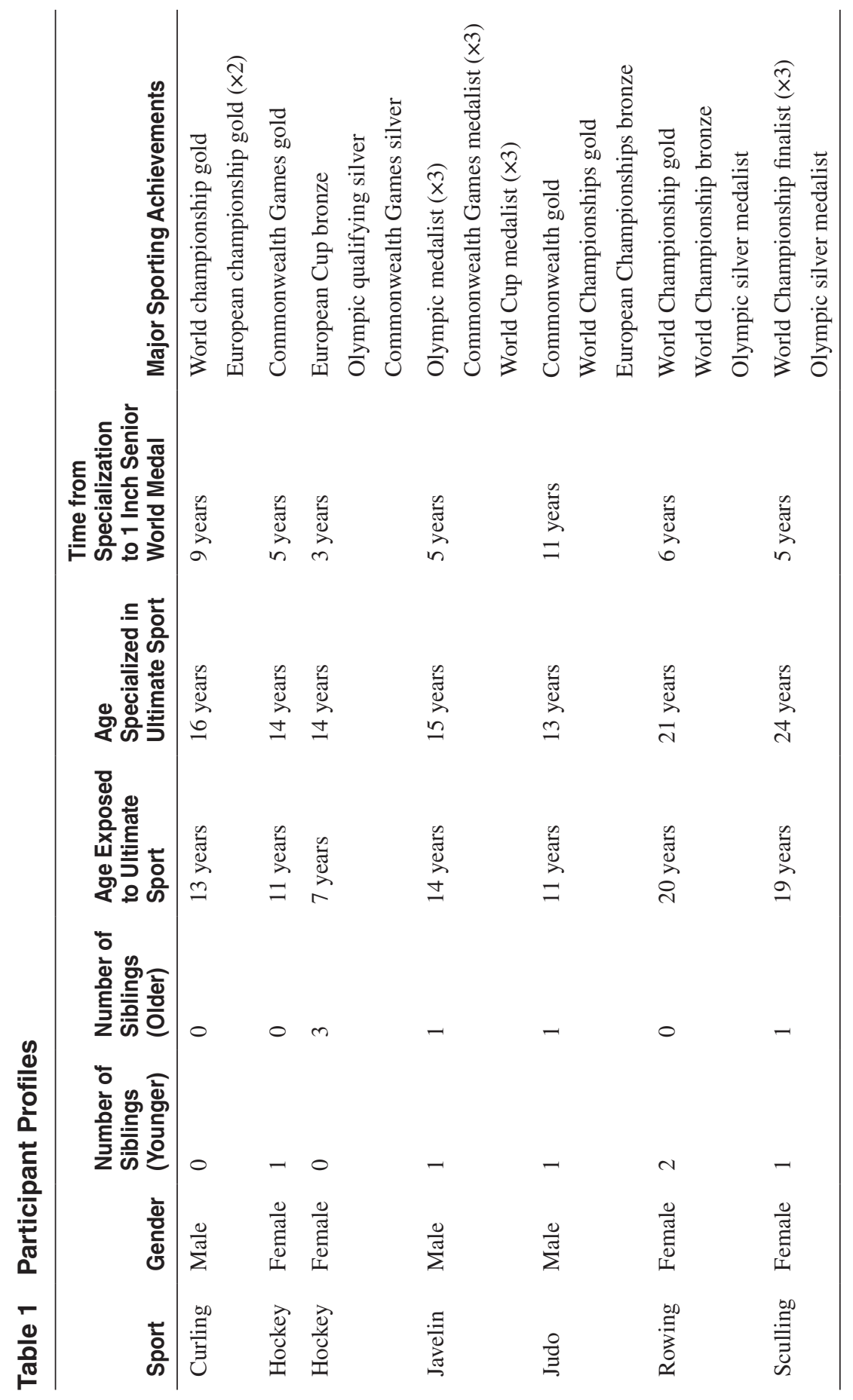




\section{Table 2 Interview Questions}

\section{Key Interview Questions}

Q1 How did you (your son/daughter) become involved in sport and progress from initial involvement to where you are (he/she is) today?

Q2 Why did you (he/she) specialize in your (his/her) sport?

Q3 When and why did you realize you (your son/daughter) had the potential to be very good at sport?

Q4 Were there any points in your (son/daughter's) development that you (he/she) found particularly difficult?

Q5 What factors distinguished you (your son/daughter) from those who did not demonstrate talent?

Q6 What factors distinguished you (your son/daughter) and other "talented" athletes who did not quite make it?

Q7 Did you (your son/daughter) face any different challenges when you were (he/she was) striving to get to the top compared with trying to remain at the top?

plausible explanation was agreed upon (Sparkes, 1998). This procedure suggested a high degree of congruence with only a small percentage of interpretations requiring discussion and all issues were solved as a result.

\section{Results and Discussion}

The purpose of this study was to identify attributes that were perceived to have contributed to the performers' development into a successful and consistent worldclass performer against the challenges they encountered as they initiated and progressed in sport. This section is subdivided into (a) factors perceived to underpin initial involvement in sport, (b) factors perceived to underpin progression in sport, and (c) factors perceived to underpin performance in sport. For convenience and clarity, the themes from Table 3 are italicised in the text.

\section{Factors Perceived to Underpin Initial Involvement in Sport}

Interviewees were asked to reflect on the attributes that facilitated their (their daughter/son) initiation and successful start in sport (see Table 3). Participants' early years experiences typically involved playing a range of activities with siblings and/or watching their parents coach or participate in various sports. Five athletes reported that sport was an integral part of their family life with parents perceived to have been a major influence on the athlete's initiation into sport. The influence of other family members was also apparent when interviewees described the interaction of the athlete with their siblings. All but one of the participants had brothers and/or sisters (see Table 1) and reported regularly taking part in sporting activities in the "back garden." All of these athletes believed that these family activities had positively facilitated their motor skill development as well as contributed to their 


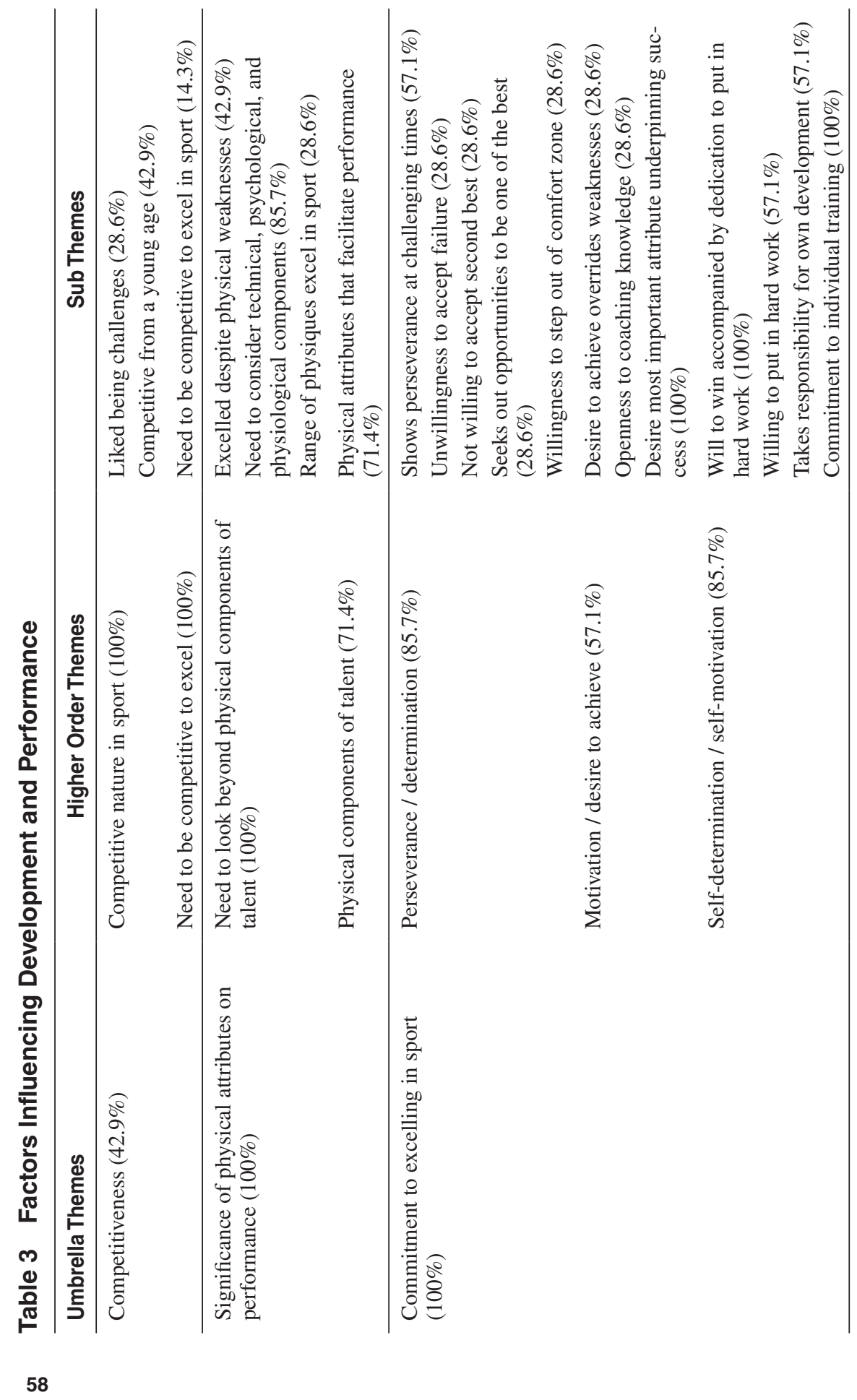




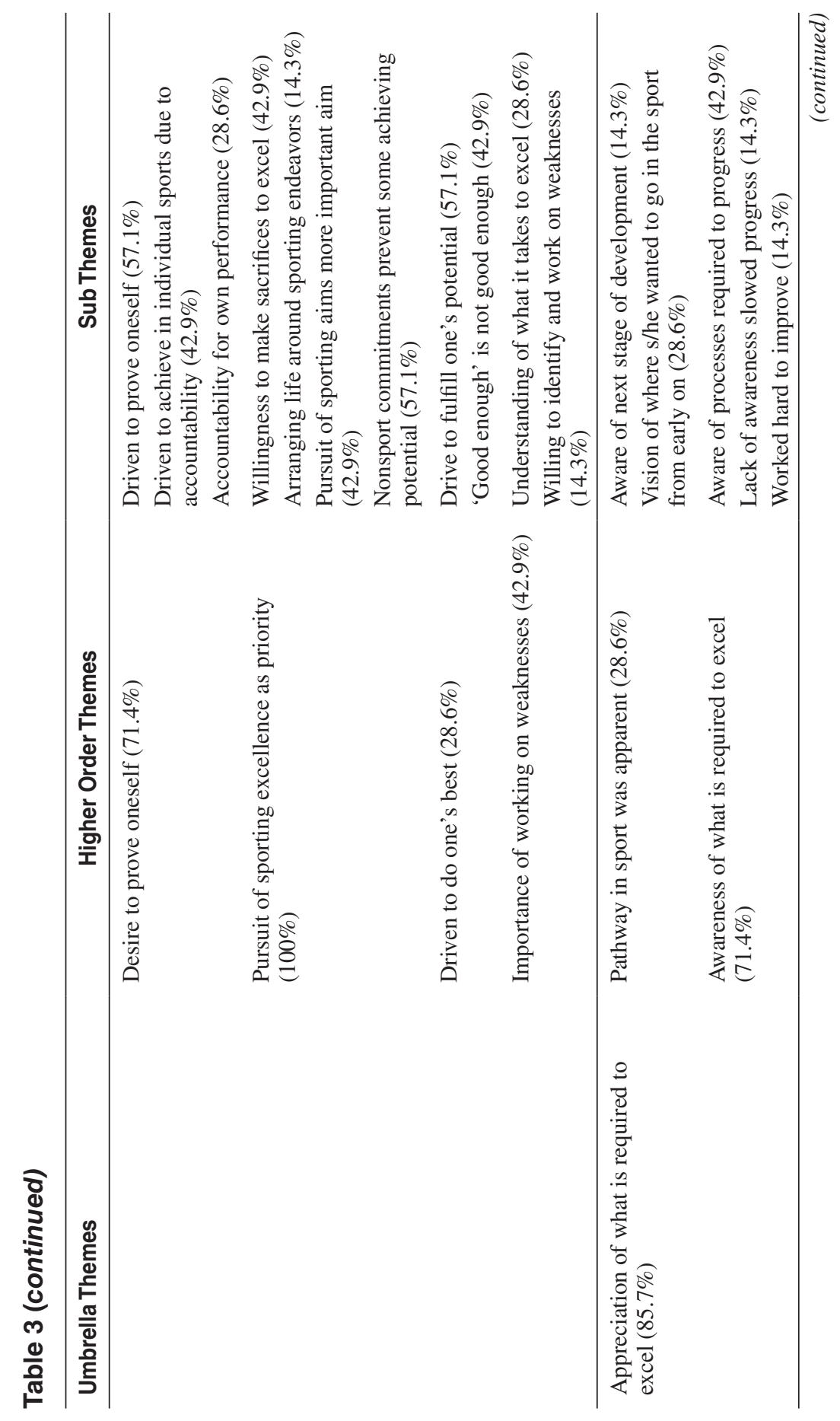




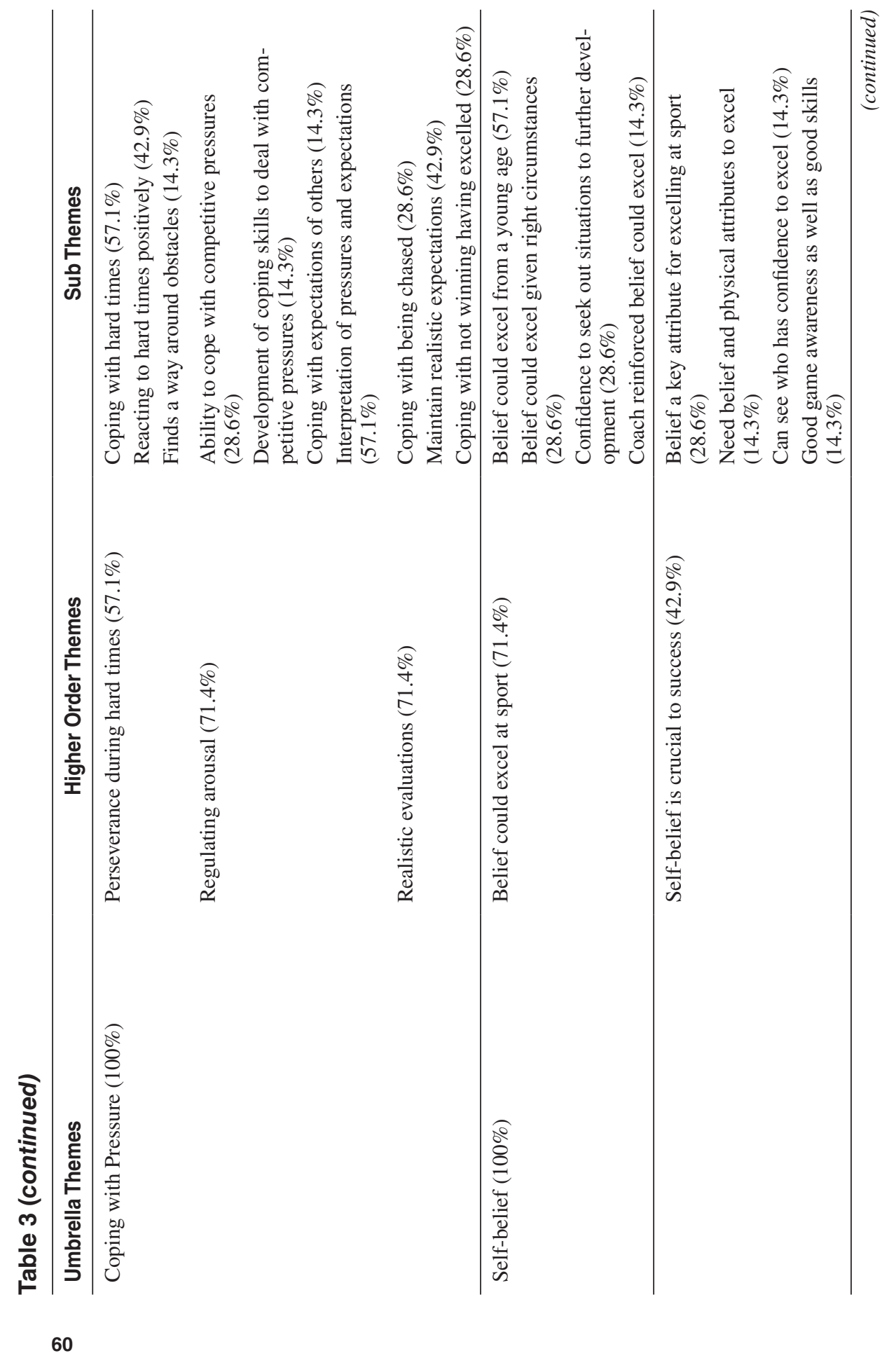




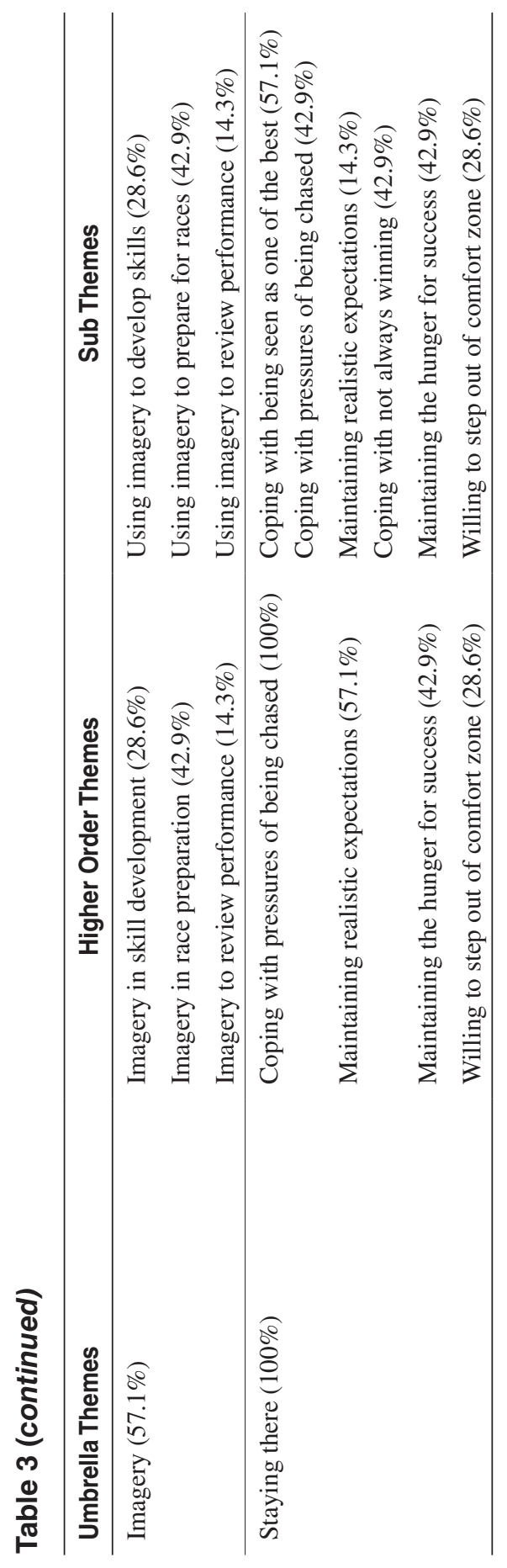


competitive nature. These findings support considerable evidence in the literature that families appear to play a crucial role in socializing individuals into sport (cf. Baker \& Horton, 2004). In addition, the early signs of a competitiveness nature for all the participants were stressed with athletes suggesting that sibling rivalry had contributed to the early development of this characteristic.

I love competing. I've got an older brother and my dad, you know, used to encourage me to beat my older brother. ... So it was never, you know, it was never easy. So yeah, from a sort of athletic perspective and on a needs basis, you know, there was lot of sequence of events through those early days [in my life] that created in a way my sort of personality now, and it's ideal for a javelin thrower. [Javelin thrower]

If his older brother, nearly 2 years older than him, if they did press ups, when his older brother did 20, [he] would do 21, you know he was that type of kid and he was a competitor, he wanted to do one better. [Javelin thrower's father]

All the athletes participated in a range of activities from an early age and this multisport activity was perceived to have contributed to their successful development within their ultimate sports:

I just look at the guys who curl with me, and there's no one who I couldn't point at and say, he's an all- round sportsman. The guys that I curl with are very very sport minded, they've all had a very broad background in sport . . . they've all got very good hand-eye co-ordination. You could put them into any sport and they will be better than average, even if they haven't played the sport before. And you could just bet your life on that because you know, they've been cricketers, badminton players, footballers - they've all excelled at something as well as curling. [Curler]

The varied early sport involvement reported by these athletes mirrors research suggesting that positive early experiences were perceived to significantly contribute to the capacity an individual has to excel within a specialist sport (cf. Barynina \& Vaitsekhovskii, 1992; Côté, Baker, \& Abernethy, 2007).

\section{Factors Perceived to Underpin Progression in Sport}

A consistent finding throughout the interviews was the extent to which psychological attributes were highlighted as a, if not the, crucial factor underpinning successful development (cf. Bompa, 1999). Of course, such responses could have accrued from participants trying to "meet the investigators' needs" (Patton, 2002). In this investigation, however, no stress was laid on any one component (e.g., physical, technical, psychological), and the participants' endorsement appeared to be genuine. Further, as well as stressing psychological characteristics, all athletes de-emphasized the significance of physical attributes in attaining excellence. In fact, all of the athletes highlighted physical weaknesses they had for their sport, and/or individuals they perceived had better physical/technical talent but failed to excel:

You come across players who are very physically gifted. Genetically they are 'ideal specimens' but I suppose it goes down to what they are prepared to put 
themselves through to gain ... it is very easy to rely on your physical attributes and not work other things. [Judo player]

The interviewees did suggest that they were driven to do their best and committed to achieving their potential from a young age. The curler compared himself to his brother-in-law who failed to achieve at the highest level due, to what he attributed to be, insufficient levels of commitment to excel in sport.

I have a brother-in-law who's very good at football and could have easily been playing professional just now. He's now playing in a very high amateur league. But he'll never make professional now, he's 29 years old, he's too late for that. But if I had had his skill, I could've been a professional [football] player. Because I'd have turned around and said, professional football, that's what I'm going to do because I'm good enough, that's what I'm going to do. He said, I really think I'm good enough to be a professional footballer but mum and dad are saying I've got to have a career. [Curler]

The sculler emphasized this point and showed an awareness of what is required to excel at the highest level that went beyond the physical characteristics toward a consideration of the desire and commitment that underpinned their successful development.

I look at people and I think that some of them think 'I' $m$ big and all I have to do is follow this training program and I'm going to be good!' That's dangerous because they haven't paid their dues in whatever it is, you know they are not putting in a $110 \%$, they are only putting in $100 \%$. I think it's because people tell them if they are big they will be good ... I think the reason these big girls don't do it is because it takes more than just size and ergo scores, it takes the desire to win and the desire you know at all costs. ... . [Sculler].

These findings support a multiplicative understanding of talent development (TD) by suggesting that, even if athletes have limitation in one area (e.g., height), they can compensate for it by strengths in another factor (e.g., commitment; Simonton, 2001). Regrettably, however, such an individual is unlikely to be selected when unidimensional TID models are employed since these fail to capture those processes performers must satisfy to achieve excellence and can provide a false early indication of talent (Vaeyens, Lenoir, Williams, \& Philippaerts, 2008). The quotation below clearly highlights the inefficiencies of 'once-off' and onedimensional approaches to TID.

Before Sydney, on the Gold Coast there was a project going on in Australia where they were going round the teams, measuring their physical attributes. They wanted to have your seated height and I wasn't even on the bottom of the scale so physically I wouldn't have made it [selection into rowing]. . . . You could select a lot of people who are potentially good at it [rowing] but actually they haven't got the correct mental attributes. [Rower (who actually medalled at that Games)]

These findings support Simonton's (2001) assertion that there is not a single genetic endowment underlying a talent domain with neither talented nor untalented individuals emerging from genetically homogenous groups. 
Psychological characteristics also underpinned the participants' decisions about specialization. For example, the sculler experienced little success during her initial exposure to rowing and therefore, having invested a considerable number of years into shot putting, it is not surprising that she continued to pursue this sport over the next 5 years. Nevertheless, there came a time when she realized that, although she was one of the best shot putters in Britain, she did not have the capacity to excel on the world stage:

I had given it [shot putting] a really good shot, hung on with the best coaches in the world and it really wasn't panning out - the rate of improvement wasn't really there. If I had carried on going year in and year out then I probably would have got there but at that rate, I wasn't going to get there. I think the highest I got was maybe 6th/5th outdoors-something like that throwing about 15.20 $/ 15.30$ [meters] . . . but to be good in the world status you had to be throwing 1920 's [19.20 meters] that's a long way off. [Sculler]

Although this athlete was not experiencing positive reinforcement from her rowing performances or coaches at this time, her realistic evaluations of her likelihood to succeed in shot putting led her to decide to specialize in rowing. Rather than deterring her from participating in rowing, this lack of reinforcement seemed only to develop an "I'll show you attitude" along with a desire to prove herself:

Mine [my ambition] was the fact that they told me I would never do it [excel in rowing] and I'd idolised sports people hugely, massive adulation you know the fact that somebody walked in this room or seen someone ... and of course then going to college and starting to rub shoulders with these famous people and realizing that I could do it and if I didn't try. . . . [Thought left hanging] [Sculler]

The father of the javelin thrower also suggested that a willingness to move out of his comfort zone and pursue excellence was a useful early indicator of his son's potential:

He wanted to be better all the time. He chased coaches, I mean I coached him only until he was English School Champion and verging on International and then he was looking for something better and although at the time it was a little bit tearful, I'd been at athletics all me life, it was obviously for the best [Javelin thrower's father]

The Judo player also believed that his ability to identify and work on his weaknesses from a young age had facilitated his development:

I would say that one of my biggest strengths is that I have always looked at the bigger picture. I am strong at doing a . . . [judo throw] . . . so I don't have to practice that every day. What I need to be doing is working on my groundwork. It is identifying your weaknesses. I would suggest that is why a lot of kids do drop out. They get to a certain level and they know that to make the next step how much [work] they are going to have to put into it [their development]. . . . In judo, it is very easy to be good, or appear good, with a couple of tricks at a young age. Kids all develop at different ages and strength comes in to it 
a lot as well but you get players that will only have a couple of things in the repertoire that they are very very good at. It is natural for them so they will maybe win five or six tournaments back-to-back just doing the same sort of thing. Then they come unstuck against someone it doesn't work against. That happens a lot in judo. A lot of coaches teach their kids how to win a tournament just doing one thing. Or they see something that is very successful and that is all they work at. But that thing is working itself, what they should be working at are the other skills. [Judo player]

In contrast to the 'professional' approach and commitment adopted by the judo player from early on in his development, the curler felt that his progress had suffered due to him not adopting such an approach:

In a team you make a team choice until you become an individual and it wasn't until we sat down, probably '93, and said, come on guys if we actually want to try and win it you know, imagine we made a go of it this year rather than just going out and having a party. And it was around that time that we started going, 'right okay, what do we want to win? Where do we think we can win?' And we looked at the whole program a little bit more scientifically instead of just pitching up at every competition and saying, oh come on let's go out and have a party. . . . It's funny because the first year that we actually sat down and we planned things out was the first year we qualified for the men's finals. [Curler]

As the athletes moved into the specialization years, they were involved in their activities to a far greater extent. Given that the focus within the sport was now on technical mastery, it was unsurprising that psychological factors were characteristic of success (Ericsson, Krampe, \& Tesch-Romer, 1993). Research posits that the relationship between these psychological characteristics and performance might be causative since they enable individuals to maximize their dispositional tendencies (Abbott \& Collins, 2004). For example, the curler did not experience early success within his sport and attributed this lack of success to a poor psychological approach to training and competing (e.g., perseverance / determination) rather than the absence of physical talent:

I'm really annoyed at myself that I wasted my first 6 years in competitive sport. Because I could've been an awful lot better and it was purely because I was having so much fun playing the sport. [Curler]

Considerable research (Lumpkin, Stoll, \& Beller, 1999) highlights how perceived competence and self-belief are important for both the uptake and maintenance of physical activity. One example is the javelin thrower who highlighted that a lack of self-belief had significantly contributed to his limited success in sports beyond javelin.

I don't think I would have shone [in any other sport but javelin]. I didn't have the belief [in other sports], I didn't have. There were people a lot better than me and I was quite, well not happy, but I accepted that they were better than me. And the javelin throwing, for some reason, if somebody beats me I don't accept that they're better than me. [Javelin thrower] 
Conversely, the rower described how the feedback and reinforcement she received increased her self-belief to achieve success in her activity:

We got a coach and he had a lot of belief in me and said 'you could be really good at this' and all of a sudden there was a sport that I seemed to excel at relative to other people. [Rower]

In a similar fashion, the judo player's decision to specialize within 2 years of first becoming involved in the sport appears to be underpinned by the positive reinforcement and subsequent self-belief he acquired from early performances in Judo.

I think I realised very quickly 'I am quite good at this'. I can tolerate the pain and if I push myself . . . I moved up the grades very quickly.

In this regard, Jess, Dewar, and Fraser (2004) highlighted how low physical activity levels post growth spurt are much more a concomitant of perceived competence than limited knowledge or even opportunity. Therefore, our research may suggest that perceived competence and self-belief are necessary attribute for individuals as they attempt to negotiate the pathway to excellence. An implication of these data are that sports that focus exclusively or predominantly on physical determinants of performance may provide little reinforcement to talented but late maturing individuals, and such processes may even lead to these individuals withdrawing from a sport before their talent is recognized. Such explanations are certainly favored by the various studies that demonstrate early birth date advantages for age group performers (e.g., Helsen, Starkes, \& Van Winckel, 1998).

While also experiencing success in other sports, the judo player relished the structure of judo which enabled him to monitor progress and be self-determined as he advanced through belt grades. This experience was in contrast to his other sport at that time, rugby, whose outcome was greatly influenced by the performance of team-mates:

I got instant gratification -3 months I was orange belt, 6 months I was blue belt and I think when I was 15 I was a black belt. I was very young. In terms of success I was always being rewarded for the effort I was putting in. I was never taking a step backwards. Through my whole career it has always been an upward curve. There has never been a dip. ... I never won anything in rugby. It is a team event . . . you are relying on other folk. Invariably no matter how good I played at rugby the other guys weren't playing as hard as I was and it could get frustrating. [Judo player]

One implication here is that a system needs to be developed within a team sports that allows an individual to monitor personal as well as team performances. The early development of effective goal setting principles that enables an individual to monitor progress may facilitate this process. Abbott and colleagues (Abbott et al., 2002) provide guidance on developing both systems and behaviors to promote effective use of psychological skills within sport specific systems. For example, if the coach wishes to encourage an athlete to monitor their own performance independently of team-mates, they could develop a system that sets individualized goals for each player. To encourage the athletes to engage in this behavior the coach should, in turn, reinforce its use by providing individualized feedback to the athletes. 
A crucial issue for athletes was their ability to cope with the inevitable setbacks experienced on the path to excellence. The ability to interpret these setbacks in a manner facilitative of development drove the athletes forward in their sports. In particular, the importance of psychological processes such as perseverance was stressed:

To become a top performer in sport, you need to understanding that when things are going well its great but when things are going badly, that is when the problems are really going to arrive. Every successful Olympic gold medalist doesn't have a plain sailing ride on the way and what makes you great is what you do when things go wrong. It took me a long time to learn that. I think if I had been aware of it a lot earlier I would have achieved things quicker. [Rower]

Athletes also reported how they typically exploited these difficult times by using them as catalysts to reassess their progress and to establish goals that would enable them to improve. For example, the hockey player, although initially distraught on learning that she had been dropped from the English squad, ultimately responded by considering what she could do to improve and ensure that she would make the squad the following year:

When I got the letter [about not being selected] I think I cried for about a whole day-locked myself in the bathroom-my mum didn't know what I was doing in there but then after that I thought I should really knuckle down and do my fitness training - I didn't use to do a lot of fitness training but I thought now I've got to take it seriously and do everything I can to rise to the next level [Hockey player].

She had been dropped at under 16 level and she turned to me and said 'mum, one day I'm going to play an Olympic game' and she said 'I am never going to fail again. [Hockey player's mother]

This ability to effectively cope with the stressors of development and regulate arousal under pressure is a key component of successful development (Côté, 1999). It can be hypothesized that the athletes who effectively deployed the psychological factors described in Table 3 coped with the challenges of development more effectively than those without those skills (Clery \& Zimmerman, 2001). Unfortunately, and reflecting many of the previous assertions, few talent development models systematically encourage the development or deployment of these skills (Petlichkoff, 2004), despite the growing support for the role of psychological factors as determinants of development (Bompa, 1999; Gould \& Chung, 2003; MacNamara et al., 2006; 2008).

An additional psychological characteristic highlighted by four of the athletes was imagery. These athletes spontaneously (i.e., not as a result of specific coaching or education) employed imagery processes from early on in their development to facilitate both their development and their ability to perform optimally in competitions. In terms of development, two of the athletes highlighted the importance of imagery. Reflecting evidence in the literature regarding imagery as a tool associated with skill development (Boyce, 1992; Waskiewicz \& Zajac, 2001), the judo player highlighted how imagery, in much the same manner as vicarious experiences can, 
enabled him to translate throws he observed other players executing into his own repertoire of skills:

I watch videos and I see things and think 'that looks quite nice, I'll try that'. Go to the club, bash about a wee bit, might not be successful and then I will sit down with the coach and say 'I have been trying to get this to work ... I'd like to work on it'. I was good at visualisation from a young age and seeing something, even just the once at a competition, I'd think 'I'll need to try that, that worked there' and 'he is a similar type of player to me so if it worked for him it should work for me'. [Judo player]

As well as athletes referring to an early use of imagery for skill development, three athletes also highlighted how their abilities to employ imagery effectively facilitated the transfer of skill to the unique competitive environment. The javelin thrower highlighted that the ability to simulate competition environments using imagery was essential within his sport:

That ability to sort of pre-create a scenario before you enact it is what sport is about. Hence, specifically javelin throwing is very much about this because you don't get the chance to throw the way you do in competition very often. ... Somebody's ability to do that is obviously different from one person to the next . . . if that [the ability to use imagery to pre-create a scenario] were easily measured I'm sure that would be a good way of finding out who could be good in a skilful, technical event such as javelin throwing. [Javelin thrower]

These psychological factors (e.g., imagery) allowed the aspiring elites to cope with the unique pressures associated with performing in novel environments (Ceci, Barnett, \& Kanaya, 2003) by optimizing development opportunities (e.g., first time appearances at a new level of competition), and effectively negotiating the transitions (e.g., selection onto teams) encountered along the pathway to excellence. The curler's example of how he used imagery to facilitate competitive performance supports this contention:

We're [the team are] looking at actually the shot before you've actually thrown the shot, you see the shot you go, 'oh what a great shot', 'oh no I didn't make that shot. Right get that out of my head'. You try it again. And you run it until you make the shot. 'Oh that's what I'll need to do, I'll just do that. [Curler]

In a similar manner, one of the athletes also reflected on how imagery helped him effectively evaluate his performances, a process identified as crucial to successful development within sport:

We do goal setting at the beginning of the year, we do constant reviews. Then we do it for individual games during the championship, we then review each game with mental imagery that goes down to shot level. [Curler]

Possibly linked to the ability of athletes to employ effective imagery, all parents highlighted how their sons/daughters were very good at recalling sporting situations and used this skill to review their performances from early on in their development:

It always amazes me how he can remember, the whole competition he can remember that stone that so and so played at the third end and that we were 
sitting a shot down. I can't even remember the third end! Yet he could have run right through the whole game and the same with the golf he would run right through the 18 holes, who played where, and what happened and why and what could have happened and what we should have done. His analysis is tremendous. [Curler's father]

I am always amazed by her ability to recall games . . . I think it [her ability to recall every part of a game] probably started as soon as she started playing somehow, yes I think it possibly is something else that is just there, I don't know how that gets there really. [Hockey player's mother]

\section{Psychological Characteristics as Determinants of Performance}

As well as highlighting the importance of psychological factors for excelling at major championships, all athletes highlighted pressures they perceived to be unique when striving to retain a major title (maintenance stage; Durand-Bush \& Salmela, 2001) and the role of psychological processes in coping with the unique pressures of 'staying there':

I remember Steve Redgrave saying 'there is one thing harder than winning. Winning is easy. It is keeping winning that is really hard.' I was like 'it is all right for you to say that isn't it!' but actually winning the world championships in' 99 (after winning in 1998) was just so difficult [after winning in 1998]

The perceived importance of psychological processes in successfully remaining at the top of one's sport is consistent with previous research that has looked at the additional pressures experienced by elite athletes (Gould, Jackson, \& Finch, 1993). An issue that reoccurred across interviews was the ability to cope with being chased (rather than doing the chasing) and to respond to this pressure by raising your own game:

I think from the ambition side you always want to be the best, want to be the best, want to be the best and I think once you're there everyone wants to beat you. And there's a massive difference in staying at the top, you have to be visibly better than the next guy. To get to the top you only just have to be better to get there. To stay there you have to be visibly better than him. Because everyone raises their game against you...so you bring out the best in your opposition. Subsequently you have to be better than their best. And that has to be your norm. [Curling]

The ability to retain realistic expectations and to accept that world beating performances cannot be produced during every competition was also highlighted as crucial for four of the athletes:

You are not infallible, everybody can be beaten. What is important is that when it comes to the big tournaments you just remember that all the times you get beaten they were for a purpose. They were training. It doesn't matter. Or when you get beat in competitions you just put it down to experience. It is about developing again. Constantly trying to justify all that you are doing.... [Curling] 
An additional issue that was stressed by two of the athletes was the recognition that continuing to excel at the top of one's sport required the willingness to move out of their 'comfort zone':

The first few competitions [after winning the National, World and European championships] we took an absolutely hammering because people just came on, they played out their socks and we went on in our, you know, normal way and said, 'right come on let's play. Everyone's playing really well against us, aren't we unlucky'. And it's not 'til you get past that - we're not being unlucky, everyone's raising their game against us and we're not raising our game past what we expect to have to raise it to, to have to beat them. So if we expect to have to play to $90 \%$ of our ability, that's where we aim for ... what we should be doing is aiming for $100 \%$ of our ability and then we'll make sure we beat them. And that's a different mindset of what you've got to do. [Curling]

This perceived effect of psychological factors on performance is consistent with research that has established psychological skills as significant preevent and in-event behaviors for successful performances within sport (Gould, Eklund, \& Jackson, 1992a, 1992b). Reflecting the athletes' thoughts on the significant effect that psychological factors can have on performance was the comment by the Javelin thrower that "At the next championships, if I had $80 \%$ physical and $100 \%$ belief I would take that rather than the other way around."

\section{General Discussion}

The emphasis placed on psychological factors by these world-class athletes is consistent with recent research in TD. For instance, research that has looked at individuals who achieve success within sport has highlighted the role of learning strategies within the development process (Kreiner-Phillips \& Orlick, 1993; Orlick \& Partington, 1998). In this particular context, Orlick (1996) highlighted that the employment of psychological processes (e.g., goal setting, planning, performance evaluation) can help athletes improve maximally from practice. Similarly, research has also established the effectiveness of employing psychological skills (e.g., goal setting, imagery) when learning a sports skill (e.g., Waskiewicz \& Zajac, 2001), dealing with difficult times (e.g., overcoming an injury; Rose \& Jevne, 1993) and competing at major events (Gould et al., 1992a, 1992b). The similarity between the current results and those characteristics found to facilitate performance at elite levels (Baker \& Horton, 2004; Gould et al., 2002;) suggests that psychological factors also play a crucial role in determining the developmental capacity of an individual.

Research in other performance domains, notably music (Kamin et al., 2006; MacNamara et al., 2006, 2008), has already established that a range of psychological factors facilitated the translation of potential into talent. Termed Psychological Characteristics of Developing Excellence (PCDEs), these are not just mental skills such as imagery or goal setting but also include the attitudes, emotions, and desires young athletes need to successfully realize their potential. Table 4 presents a summary list of the PCDEs established in the current results against the findings of other investigations (Kamin et al., 2006; MacNamara et al., 2006, 2008) illustrating the similarity between the two domains. There appears to be considerable overlap between the two lists. Nevertheless, the deployment of PCDEs may be 


\section{Table 4 Psychological Characteristics of Developing Excellence}

\begin{tabular}{ll}
\hline $\begin{array}{l}\text { PCDEs Established in the Literature } \\
\text { (e.g., MacNamara et al., 2006, 2008; } \\
\text { Kamin et al., 2006) }\end{array}$ & PCDEs Established in This Study \\
\hline Motivation & Competitiveness \\
Commitment & Commitment \\
Goal setting & Vision of what it takes to succeed \\
Quality practice & Imagery \\
Imagery & Importance of working on weaknesses \\
Realistic performance evaluations & Coping under pressure \\
Coping under pressure & Game awareness \\
Social skills & Self-belief \\
\hline
\end{tabular}

complicated by the dynamic, individualized, and complex nature of the "pathway to excellence'. Accordingly, before the potentially substantial benefits of PCDE-based TID processes may be realized, it is important to establish differences (if any) in the set of behaviors required at different points during development and/or within different performance domains. Checking for such time and environment-based differences was the focus for the second part of this investigation (MacNamara et al., 2010).

\section{References}

Abbott, A., \& Collins, D. (2002). A theoretical and empirical analysis of a 'state of the art' talent identification model. High Ability Studies, 13(2), 157-178.

Abbott, A., \& Collins, D. (2004). Eliminating the dichotomy between theory and practice in talent identification and development: considering the role of psychology. Journal of Sports Sciences, 22, 395-408.

Abbott, A., Button, C., Pepping, G-J., \& Collins, D. (2005). Unnatural selection: Talent identification and development in sport. Nonlinear Dynamics Psychology and Life Sciences, 9, 61-88.

Bailey, R., \& Morley, D. (2006). Towards a model of talent development in physical education. Sport Education and Society, 11, 211-230.

Baker, J., \& Horton, S. (2004). A review of primary and secondary influences on sport expertise. High Ability Studies, 15, 211-228.

Barynina, I.I., \& Vaitsekhovskii, S.M. (1992). The aftermath of early sports specialization for highly qualified swimmers. Fitness and Sports Review International, 27, 132-133.

Bloom, B.S. (1985). Developing talent in young people. New York: Ballantine.

Bompa, T. (1999). Periodization: The theory and methodology of training (4th ed.). Champaign, IL: Human Kinetics.

Boyce, B.A. (1992). The effects of goal proximity on skill acquisition and retention of a shooting task in a field-based setting. Journal of Sport \& Exercise Psychology, 14, 298-308.

Ceci, S.J., Barnett, S.M., \& Kanaya, T. (2003). Developing childhood proclivities into adult competencies: The overlooked multiplier effect. In R.J. Sternberg \& E.L. Grigorenko (Eds.), The psychology of abilities, competencies, and expertise (pp. 126-158). Cambridge, England: Cambridge University Press. 
Cleary, T.J., \& Zimmerman, B.J. (2001). Self-regulation differences during athletic practice by experts, non-experts, and novices. Journal of Applied Sport Psychology, 13, 61-82.

Côté, J. (1999). The influence of the family in the development of talent in sports. The Sport Psychologist, 13, 395-417.

Côté, J., Baker, J., \& Abernethy, B. (2007). Play and practice in the development of sport expertise. In G. Tenenbaum \& R.C. Eklund (Eds.), Handbook of Sport Psychology (pp. 184-202).

Côté, J., Salmela, J.H., Baria, A., \& Russell, S.J. (1993). Organizing and interpreting unstructured qualitative data. The Sport Psychologist, 6, 55-64.

Durand - Bush, N., \& Salmela, J.H. (2002). The development and maintenance of expert athletic performance: Perceptions of world and Olympic champions. Journal of Applied Sport Psychology, 14, 154-171.

Ericsson, K.A., \& Charness, N. (1994). Expert performance: Its structure and acquisition. The American Psychologist, 49, 725-747.

Ericsson, K.A., Krampe, R.T., \& Tesch-Romer, C. (1993). The role of deliberate practice in the acquisition of expert performance. Psychological Review, 100, 363-406.

Feldman, D.H. (1988). Creativity, dreams, insights, and transformation. In R.J. Sternberg (Ed.), The nature of creativity. New York: Cambridge University Press.

Gould, D., \& Chung, Y. (2004). Self-regulation in young, middle and older adulthood. In M.R. Weiss (Ed.), Developmental sport psychology and exercise psychology: A lifespan perspective (pp. 383-402). Morganton, WV: Fitness Information Technology.

Gould, D., Diffenbach, K., \& Moffett, A. (2002). Psychological characteristics and their development in Olympic champions. Journal of Applied Sport Psychology, 14, 172-204.

Gould, D., Jackson, S., \& Finch, L. (1993). Sources of stress in national champion figure skaters. Journal of Sport \& Exercise Psychology, 15, 134-159.

Gould, D., Eklund, R.C., \& Jackson, S.A. (1992a). 1988 U.S. Olympic wrestling excellence: I. mental preparation, precompetitive cognition, and affect. The Sport Psychologist, 6, 358-382.

Gould, D., Eklund, R.C., \& Jackson, S.A. (1992b). 1988 U.S. Olympic wrestling excellence. Thoughts and affect occurring during competition. The Sport Psychologist, 6, 383-402.

Helsen, W.F., Starkes, J.L., \& Van Winckel, J. (1998). The influence of relative age on success and dropout in male soccer players. American Journal of Human Biology, 10, 791-798.

Howe, M.J.A., \& Davidson, J.W. (2003). The early progress of able young musicians. In R. J., Sternberg \& E. L.Grigorenko (Eds.). The Psychology of Abilities, Competencies and Expertise: Cambridge University Press.

Jess, M., Dewar, K., \& Fraser, G. (2004). Basic moves: Developing a foundation for lifelong physical activity. British Journal of Teaching Physical Education, 35, 2-5.

Kamin, S., Richards, H., \& Collins, D. (2007). Influences on the talent development process of non-classical musicians: psychological, social and environmental influences. Music Education Research, 9, 449-468.

Kunst, G., \& Florescu, C. (1971). The main factors for performance in wrestling. Bucharest: National Sports Council.

Krane, V., Andersen, M.B., \& Strean, W.B. (1997). Issues of qualitative research methods and presentation. Journal of Sport \& Exercise Psychology, 19, 213-218.

Kreiner-Phillips, K., \& Orlick, T. (1993). Winning after winning: the psychology of ongoing excellence. The Sport Psychologist, 7, 31-48.

Lidor, R., \& Lavyan, N.Z. (2002). A retrospective picture of early sport experiences among elite and near-elite Israeli athletes: developmental and psychological perspectives. International Journal of Sport Psychology, 33, 269-289.

Lumpkin, A., Stoll, S.K., \& Beller, J.M. (1999). Sport ethics: Applications for fair play (2nd ed.). St. Louis: McGraw-Hill.

MacNamara, A., Button, A., \& Collins, D. (under review).The role of psychological characteristics in facilitating the pathway to elite performance. Part 2: Examining environmental and stage related differences in skills and behaviours. The Sport Psychologist. 
MacNamara, A., Holmes, P., \& Collins, D. (2006). The pathway to excellence: The role of psychological characteristics in negotiating the challenges of musical development. British Journal of Music Education, 23, 80-98.

MacNamara, A., Holmes, P., \& Collins, D. (2008). Negotiating transitions in musical development: The role of psychological characteristics of developing Excellence. Psychology of Music, 36, 335-352.

Orlick, T., \& Partington, J. (1998). Mental links to excellence. The Sport Psychologist, 2, $105-130$.

Orlick, T. (1996). The wheel of excellence. Journal of Performance Education, 1, 3-18.

Patton, M.Q. (2002). Qualitative research and evaluation methods (3rd ed.). Thousand Oakes, CA: Sage.

Petlichkoff, L.M. (2004). Self-regulation skills in children and adolescents. In M.R. Weiss (Ed.), Developmental sport and exercise psychology: A lifespan perspective (pp. 273-292). Morgantown, WV: Fitness Information Technology.

Regnier, G., Salmela, J.H., \& Russell, S.J. (1993). Talent detection and development in sport. In R.N. Singer, M. Murphey, \& L.K. Tennant (Eds.), Handbook of research on sport psychology (pp. 290-313). New York: Macmillan.

Renzulli, J.S. (1986). The three-ring conception of giftedness: A developmental model for creative productivity. In R.J. Sternberg \& J. Davidson (Eds.), Conceptions of Giftedness (pp. 53-92). New York: Cambridge University Press.

Rose, J., \& Jevne, R.F.J. (1993). Psychosocial processes associated with athletic injuries. The Sport Psychologist, 7, 309-328.

Simonton, D.K. (2001). Talent development as a multidimensional, multiplicative, and dynamic process. Current Directions in Psychological Science, 10, 39-43.

Singer, R.N., \& Orbach, I. (1999). Persistence, excellence, and fulfilment. In R. Lidor \& M. Bar-Eli (Eds.), Sport psychology: linking theory and practice (pp. 167-191). Morgantown, Bookcrafters.

Schoon, I. (2000). Towards a dynamic-interactive model of talent development: A Life-Span Perspective. In K.A. Heller, F.J. Mönks, R. Sternberg, \& R. Subotnik (Eds.), International Handbook of Giftedness and Talent (pp. 213-225). Oxford: Pergamon Press.

Sparkes, A.C. (1998). Validity in qualitative inquiry and the problem of criteria: Implications for sport psychology. The Sport Psychologist, 12, 363-386.

Strauss, A., \& Corbin, J. (1998). Basics of qualitative research. Thousands Oaks, CA: Sage.

Thomas, K.T., \& Thomas, J.R. (1999). What squirrels in the trees predict about expert athletes. International Journal of Sport Psychology, 30, 221-234.

Van Tassel -Baska, J. (2001). The talent development process: What we know and what we don't know. Gifted Education International, 16, 20-28.

Vaeyens, R., Lenoir, M., Williams, M., \& Philippaerts, R. (2008). Talent identification and development programmes in sport: Current models and future directions. The Journal of Sports Medicine, 38, 703-714.

Ward, P., Hodges, N.J., Williams, A.M., \& Starkes, J. (2004). Deliberate practice and expert performance: defining the path to excellence. In A.M. Williams \& N.J. Hodges (Eds.), Skill acquisition in sport: research, theory and practice (pp. 231-258). London: Routledge.

Waskiewicz, Z., \& Zajac, A. (2001). The imagery and motor skills acquisition. Biology of Sport, 18, 71-83.

Williams, J.M., \& Krane, V. (2001). Psychological characteristics of peak performance. In J.M. Williams (Ed.), Applied sport psychology: Personal growth to peak performance. Mountain View, CA: Mayfield. 